\title{
WHY A FEW SOCIAL NETWORKING SITES SUCCEED WHILE MANY FAIL
}

\author{
Arash Abolghasemi Kordestani, Lulea University of Technology, Sweden \\ Moez Limayem, University of Arkansas, USA \\ Esmail Salehi-Sangari, Royal Institute of Technology (KTH) \& Lulea University of Technology, Sweden \\ Henrik Blomgren, Royal Institute of Technology, Sweden \\ Afshin Afsharipour, Lulea University of Technology, Sweden
}

\begin{abstract}
The purpose of this research is to study why a few social networking sites (SNSs) succeed, while many others fail. Collecting data from 89 Facebook users reveals that electronic word of mouth (EWOM), ease of use, source credibility, information usefulness, and user participation contribute to the success of SNSs.
\end{abstract}

\section{INTRODUCTION}

Ever-increasing numbers of users visit social networking sites (SNSs) for interaction and information sharing. Facebook, Twitter, and MySpace are three popular SNSs; Facebook is the most attractive SNS, with more than 500 million users (Sorkin 2010). Why has Facebook succeeded, while many of its rivals have failed? What has enabled this site to achieve a competitive advantage? This study makes meaningful contributions to research and practice in the social networking field by answering this research question.

\section{THEORETICAL FRAMEWORK}

The technology acceptance model (TAM) has paramount importance in research about SNSs (Hossain and de Silva 2009), and it is used in this study. However, using TAM only might not describe what happens in consumer communities (Baron et al. 2006). Former studies included other factors in the body of TAM to improve its interpretation. Shin (2010) incorporated internal and external motivators to investigate behavior among online social network users. Lee et al. (2003) considered social influence in technology acceptance. Hossain and de Silva (2009) focused on social structures, and included the influence of one's social ties in the acceptance of social networks.

User participation, also known as membership continuance intention, has significant implications for marketing activities [19]. Participation in virtual online communities causes users to engage more in community activities, which increases their loyalty to both providers and the community (Koh and Kim 2004). Because switching costs are negligible in a social network setting, members' participation and decision to prolong their membership provide the most interesting issues to consider. Thus, the success factors are formulated according to user participation concepts. However, this definition of success implicitly implies that an SNS with a small number of users is not successful.

We also include information usefulness because of its implications for information adoption (Sussman and Siegal 2003) and its ability to compensate for some of the limitations regarding knowledge sharing in previous models (Koh and Kim 2004). Finally, our model examines the credibility of the information source because it is important but largely overlooked (Sussman and Siegal 2003). We offer a schematic presentation of a research model pertaining to the association among user participation, information usefulness, electronic word of mouth (EWOM), ease of use, and credibility of the social network in figure 1.

\section{METHOD}

An online survey was used to collect data from individual Facebook users. Corporate users were not included in our data collection. An online invitation and a questionnaire were sent within a message to 265 Facebook users. One hundred and three questionnaires were filled in. After deleting questionnaires in which there were more than five missing responses, 89 cases remained. Therefore, our response rate was $34 \%$. According to our analysis, the smallest acceptable sample size would be 20 (Chin and Newsted 1999). Demographic analysis informed us that 52 percent of the respondents had master's degrees while 33 percent of them had bachelor's degrees. About 30 percent of the respondents spent up to 30 minutes on Facebook every day while 25 percent of them actively interacted with Facebook for up to one hour a day. The favorite activity was to watch friends' photos or videos (57 percent of respondents) and then checking events announcements (12 percent). 
All scales of this study are taken from former studies, with minor adjustments to fit the context of SNSs. The presence of several dependent and independent variables with different types of relationships prompted us to choose structural equation modeling (Hair et al. 2009), together with SPSS and smartPLS (Ringle and Wende 2005). The survey questions used Likert scales (Van Laerhoven et al. 2004).

\section{RESULTS AND DISCUSSIONS}

We used a cross-loading test of each indicator and found that all loadings were greater than 0.6, with no high cross-loadings in either data set. In the measurement model for the whole sample, all variables have average variance extracted (AVE) values greater than 0.5 and composite reliabilities greater than 0.7 . To calculate discriminant validity, we used a crosscorrelation matrix. The square root of the AVE is greater than the correlation of any construct with any others. We depicted the path coefficients, their significance levels, and $\mathrm{R}^{2}$ in figure 1 . Approximately $20 \%$ of the variance in information usefulness stemmed from ease of use and source credibility. EWOM and information usefulness accounted for $24 \%$ of user participation in Facebook. In contrast with previous findings on negative EWOM (Sen and Lerman 2007) and discussions of the difficulty of freezing EWOM issues (Trusov et al. 2009), we find a positive effect in Facebook; in line with previous studies (Casalo et al. 2008), we reveal the importance of this factor for bringing users together and activating inactive users. Our data explain $22 \%$ of the usefulness of information on Facebook, and that usefulness depends on ease of use. Users were never confused or bored with the SNS. They could solve usage problems easily and considered the SNS easy to use. This ease of use related closely to their ability to define the information on their SNS as valuable, informative, and helpful (Sussman and Siegal 2003).

\section{CONCLUSION AND IMPLICATIONS}

We have tried to determine why some SNSs are successful while others are not. Several factors motivate users to participate, including EWOM, ease of use, credibility of the source, and information usefulness. These factors also affect one another simultaneously. When successful SNSs have more users participating in their activities, they benefit from EWOM for acquiring other potential users. In addition, valuable, informative, and helpful information in SNSs motivates users to participate in social activities on the sites. This usefulness of information depends on the profile of the users and ease of use. That is, information sources in SNS are other users, and the level of their knowledge, expertise, trustworthiness, and reliability dictates the usefulness of the information they post. In addition, we have determined that when users encounter complexity while working with SNS or become confused about how to use it, they do not find the information useful or simply ignore it. If users perceive low usefulness of the information of an SNS, they will not be interested in participating in it.

Some SNSs succeed or fail based on user participation. Successful SNSs have highly active participants, and feature EWOM that attracts other potential users. SNS marketers might, therefore, pay attention to the presence of useful information on their SNS that could persuade users to stay. This study of Facebook users has indicated that information usefulness encourages users to participate. Because ease of use of an SNS affects the usability of the information on that site, marketers may

consider this factor, and site developers may improve readability of information to enhance users' participation in social networking activities.

\section{REFERENCES}

Baron, S., Patterson, A., \& Harris, K. (2006). Beyond technology acceptance: Understanding consumer practice. International Journal of Service Industry Management, 17(2), 111-135.

Casalo, L. V., Cisneros, J., Flavian, C., \& Guinaliu, M. (2008). Determinants of success in open source software networks. Industrial Management and Data System, 109(4), 532-549.

Chin, W. W., \& Newsted, R. R. (1999). Structural equation modeling analysis with small samples using partial least squares. Statistical Strategies for Small Sample Research, 307-341. 
Hair, J. F., Black, W. C., Babin, B. J., Anderson, R. E., \& Tatham, R. L. (2009). Multivariate Data Analysis. New Jersey: Pearson Education.

Hossain, L., \& de Silva, A. (2009). Exploring user acceptance of technology using social networks. Journal of High Technology Management Research, 20, 1-18.

Koh, J., \& Kim, Y.-G. (2004). Knowledge sharing in virtual communities: an e-business perspective. Expert Systems with Applications, 26(2), 155-166.

Lee, J.-S., Cho, H., Gay, G., Davidson, B., \& Ingraffea, A. (2003). Technology acceptance and social networking in distance learning. Educational Technology \& Society, 6(2), 50-61.

Ringle, C. M., Wende, S., \& Will, S. (2005). SmartPLS 2.0 (M3) Beta, Hamburg, Available from: http://www.smartpls.de.

Sen, S., \& Lerman, D. (2007). Why are you telling me this? An examination into negative consumer reviews on the web. Journal of Interactive Marketing, 21(4), 76-94.

Shin, D.-H. (2010). Analysis of online social networks: a cross-national study. Online Information Review, 34 (3), $473-495$.

Sorkin, A. R. (2010). Facebook tops 500 million users. New York Times Blog, July, B8. http://www.nytimes.com/2010/07/22/technology/22facebook.html?_r=1\&dbk

Sussman, S. W., \& Siegal, W. S. (2003). Informational influence in organizations: an integrated approach to knowledge adoption. Information Systems Research, 14(1), 47-65.

Trusov, M., Bucklin, R. E., \& Pauwels, K. (2009). Effects of word-of-mouth versus traditional marketing: findings from an internet social networking site. Journal of Marketing, 73, 90-102.

Van Laerhoven, H., Van der Zaag-Loonen, H. J., \& Derkx, B. H. F. (2004). A comparison of Likert scale and visual analogue scales as response options in children's questionnaires. Acta Paediatrica, 93(6), 830-835.

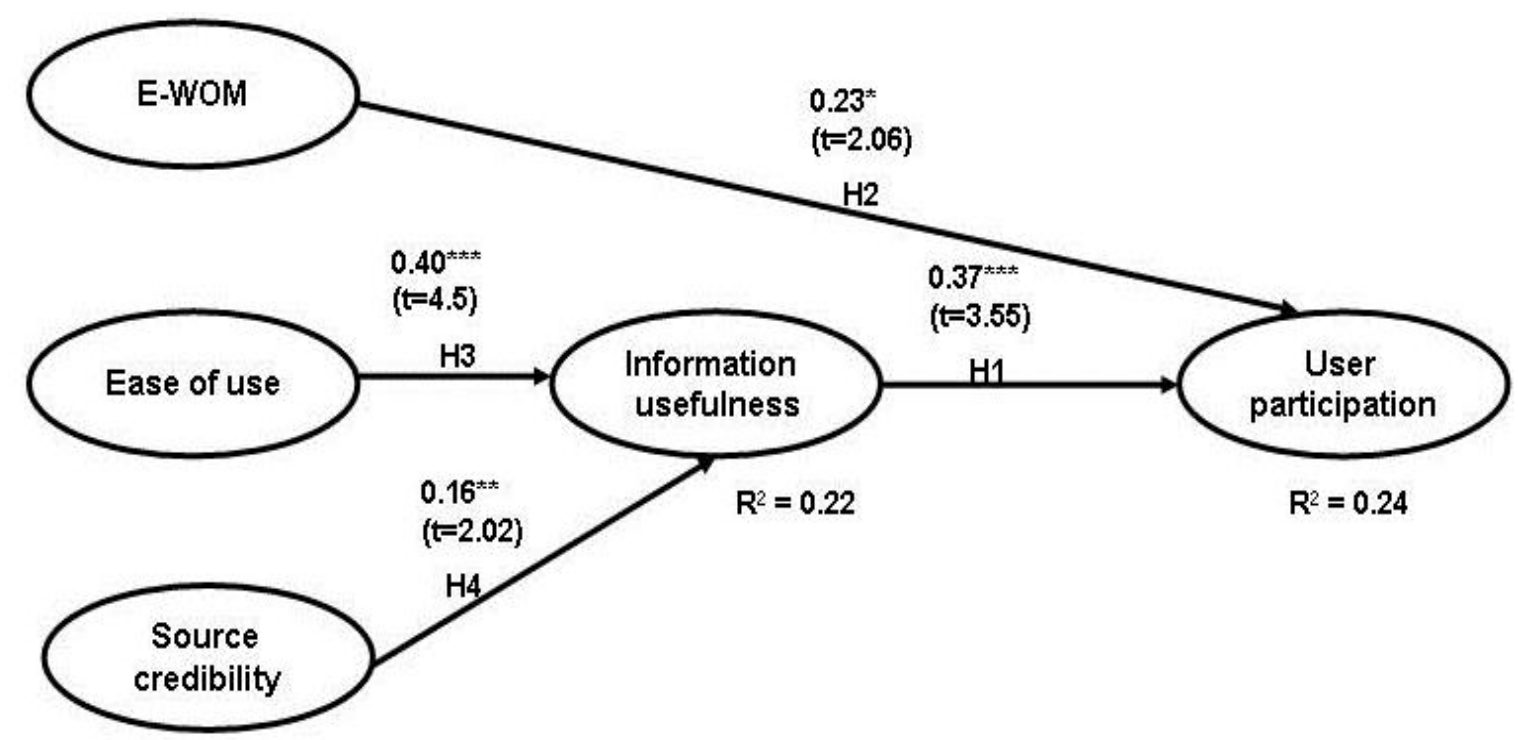

Figure 1: Research model and structural model results 